\title{
WHO WOULD EAT MORE WITH A FOOD VOUCHER PROGRAMME In South Africa? \\ Jan $\mathbf{H}$ van Heerden \\ Department of Economics, University of Pretoria
}

\begin{abstract}
A Computable General Equilibrium model is used to find the effects of a food voucher scheme on the economy in South Africa. If firms consider the issuing of vouchers as increased remuneration, they will hire fewer labourers. The higher labour cost increases the total cost of production and lowers supply. Real Gross Domestic Product decreases and the economy becomes worse off. However, depending on the size of the government's involvement in such a scheme as well as the tax policies that are used to fund it, a food voucher scheme could benefit the poor, and improve the distribution of wealth in the country.
\end{abstract}

JEL D58

\section{1}

\section{Introduction}

The Institute of International Social Cooperation (ICOSI) (2001) claims that the use of food vouchers by countries that implement them in Europe helps to both (i) increase Gross Domestic Product (GDP), and (ii) eradicate poverty. Other reports on food voucher schemes in Lithuania (Ernst \& Young, 2004) and from the Ukraine (International Centre for Policy Studies, 2003) also encourage the use of food voucher schemes. The purpose of this paper is to investigate whether a food voucher scheme would be able to both increase GDP and eradicate poverty in South Africa. A Computable General Equilibrium (CGE) model is used to estimate what the effects of such a system would be on the economy. It is important to use a general equilibrium model to follow the total effects of such a scheme, since it highlights the effects on all the role players and all equilibrium commodity prices and quantities in the economy. It is therefore not surprising that the results of this paper differ from the studies mentioned above, as a result of making use of general equilibrium techniques, as well as making realistic assumptions about economic behaviour. The next section provides a brief description of the model used, followed by the assumptions made and scenarios tested. The fourth section calculates the target variables. The fifth section provides the results of the study and the final section concludes the paper.

\section{2}

\section{The general model}

The model is similar to the ORANI-G general equilibrium model of the Australian economy, and is written and solved using GEMPACK (Harrison \& Pearson, 1996). It is a typical CGE model where all the markets in the economy start in simultaneous equilibrium, where supply is equal to demand. Shocks are applied to some exogenous variables of the model and then all prices and quantities adjust until a new equilibrium is reached. In two dimensional space it would be like shifting a supply or demand curve and to find a new equilibrium where the new curves intersect. The CGE modeller studies the new equilibrium and tries to explain the deviations from the initial equilibrium. In general, the model allows for limited substitution on the production side, while it focuses on substitution in consumption. 
It is a static model with an overall Leontief production structure and Constant Elasticity of Substitution (CES) sub-structures for (i) the choice between labour, capital and land; (ii) the choice between the different labour types in the model; and (iii) the choice between imported and domestic inputs into the production process. This means that overall production of commodities takes place using fixed proportions of inputs, with some flexibility in the choices of factors of production, as well as the origin of the inputs into the production processes. Household demand is modelled as a linear expenditure system (LES) that differentiates between necessities and luxury goods, while households' choices between imported and domestic goods are modelled using the CES structure. The LES means that households would first choose subsistence levels of basic commodities that they wish to consume, and with the remaining money, they choose luxury commodities based on their prices and the elasticities of demand.

The model was originally based on the official 1998 social accounting matrix (SAM) of South Africa, published by Statistics South Africa (SSA, 2001), but since that period, the database has been updated and expanded. The SSA SAM divides households into 12 income groups and 4 ethnic groups, and distinguishes 27 sectors. For the purpose of this study, I use an extended version of the SAM, with 39 industries and 39 commodities. The elasticities used for the CES functions in the model have been taken from De Wet (2003).

The model's closure rules reflect a short-run time horizon. The capital stock is assumed to be fixed, while the rate of return on capital is allowed to change. Labour supply could be modelled in two ways: (i) by employing an elastic supply of labour as in the traditional short-run closure for CGE models; or (ii) by modelling skilled and unskilled labour differently. This paper comments on the former. The model differentiates between 11 different labour groups that are classified as either skilled or unskilled. Skilled labour could be treated as human capital with inelastic short-term supply, or assumed perfectly elastic alongside unskilled labour, with fixed real wages. The supply of land is also assumed to be inelastic.
With reference to the macroeconomic variables, it is assumed that aggregate investment, government consumption and inventories are exogenous, while private consumption and the trade balance are endogenous. (All the variables are given in change or per cent change form, and 'exogenous' here means they do not change between equilibria). This specification allows one insight into the effect of the suggested policies on South Africa's consumption and competitiveness. All technological change variables and all tax rates are exogenous to the model, except for the consumers' tastes for food related commodities, which are endogenised. Under normal circumstances consumers' tastes would also be exogenous and not change in the presence of policy shocks. They would continue to consume the same subsistence amounts of all commodities, and buy more luxury goods if their wages increase. In order to compare my results with those in the cited literature, however, I hypothesise that by setting a target of food consumption increase, and allowing the taste variable to adjust until the target is reached, consumers would consume more food.

\section{3}

\section{Modelling the implementation of a food voucher scheme - assumptions and scenarios}

An examination of the study, "Meal vouchers, a tool serving the interests of the social pact in Europe", by ICOSI (2001), reveals that to some degree employers' contributions to food vouchers are usually tax deductible. It would be quite unreasonable to expect firms to voluntarily pay for the food vouchers of their employees, without their expenses being compensated. However, according to Wanjek (2005) there are firms in Brazil and Hungary that $d o$ voluntarily give food vouchers to their workers. In this paper it is assumed that the government funds a portion of the food voucher scheme and then persuades firms to contribute the difference.

The second assumption is that firms would consider their contribution toward the food voucher scheme as paying higher wages. Firms pay workers a certain amount. I model this 
total labour cost to the firm as one expense, and assume this is how the firms classify it as well. So, why should an economist expect that food vouchers would not completely offset monetary wages?

The third assumption is that employees buy food with the vouchers, and not necessarily restaurant meals. That is, I model the effect of "food vouchers" rather than "meal vouchers" on the South African economy. However, it would be quite unrealistic to assume that the total expenditure on food would increase by the amount that employees receive in the form of food vouchers. As firms have a certain perception of their total expenditures, households have a similar perception in terms of an increase in total remuneration. Consider the behaviour of two fictitious persons.

Previously, person A had no lunch, and spends R20 on food after receiving a R20 voucher. Person B, however, used to spend R20 of his own money on lunch and now instead uses the R20 voucher for lunch. The R20 that he has saved, he now uses to buy other things, so that food expenditure does not increase at all. Most of the studies that I have seen on food vouchers in Europe and Eastern Europe assume that spending on food will increase by the value of the vouchers, which is unrealistic. It should increase by the marginal propensity to consume food times the value of the vouchers. Economists would indeed expect that consumers would merely act as if their total wages have increased, and not spend the extra income only on food. I make the very strict assumption that consumers' marginal propensity to consume food is 80 per cent.

A fourth assumption is that the government would raise new taxes to pay for the food voucher scheme. In much of the literature the authors assume the vouchers to be manna from heaven, and hence they get very positive results from the implementation of food voucher schemes.

So, there are five explicit assumptions made in the paper, which are directly translated into the model equations (See Appendix):

(i) The size of the voucher scheme is a proportion of the starting value of total expenditure on food, retail trade and hotels. This is a trivial assumption and any size of the scheme can easily be modelled - size does not matter here.

(ii) The government funds a portion of the food voucher scheme. I discuss the results of government funding ranging from 0 to 100 per cent.

(iii) A proportion of the value of food vouchers may not be spent on food. The database indicates that households spend between 20 and 65 per cent of their incomes on food, depending on how affluent they are. If they receive extra "remuneration", they would probably not spend 100 per cent of that on food, whether the remuneration is in terms of money or vouchers. In this exercise, I assumed that they would spend 80 per cent of the value of vouchers on food, which is quite high.

(iv) The prices of food are not manipulated, but determined by demand and supply forces, so I adjust the behaviour of households so that they would like food better and consume relatively more of it, endogenously. (Endogenously means that the model calculates how much the preference for food must increase to obtain the result of 80 per cent marginal propensity to consume food.)

(v) I increase the indirect tax rates on all non-food commodities to pay for the government's contribution to the voucher scheme. This is debatable and could be a topic for future research, in the form of a study that investigates the most efficient and equitable way to finance the voucher scheme.

Other assumptions are also made about the variables in the model, and these assumptions will always influence the outcome of the exercises. For example, this entire exercise is completed for the short-run. I am studying the effects of a voucher scheme during the first few years of implementation, and therefore do not at this stage allow for technological changes or changes in producer behaviour, amongst other things. The additional model equations for the food voucher exercise are provided in the Appendix. 


\section{4 \\ Target variables}

A number of target variables are calculated by the model, and utilised as instruments to guide my conclusions, namely (i) GDP, (ii) employment, (iii) total consumption and more specifically, consumption by the poor, (iv) exports and imports, and obviously, (v) the effect on the food industry. I generally compare the macroeconomic variables by implementing the concept of "marginal excess burden" (MEB), which is the change in a real macroeconomic variable divided by the change in real government revenue. If one has to compare two possible policy scenarios, it is important to "scale" the results such that they are comparable. One way of doing that is to calculate the effect on a target variable per Rand of government revenue gained or lost. Policy X might let GDP grow by 60c while government revenue decreases by R1, while policy Y might let GDP grow by 70c with a R1.50 decrease in revenue. Then I would generally say that policy $\mathrm{X}$ is better in terms of GDP per unit of revenue, even though the absolute value of the GDP is larger under policy Y. The outcomes might be the other way around in terms of another target variable such as total consumption, in which case it becomes a political decision whether to implement policy X or Y.

\section{5}

\section{Results}

In this section I present only a few of the most important results, which would vary depending on the combinations of assumptions implemented. For example, I compare the scenarios where firms fund large proportions of the food voucher scheme to ones where the government carries the greater burden.

One advantage of using a CGE model for a study like this is that I am able to capture the full circle of the flow of "funds" associated with the food voucher scheme. (Money is not explicitly modelled in a CGE model, but I do think in terms of transactions taking place while prices and interest rates are determined in the economy). There are three components to the circuit, linked to the three "players" in the game: (i) firms increase their payments to employees in the form of food vouchers; (ii) employees receive higher remuneration packages from their employers and spend more on food (and other commodities as well); and (iii) the government subsidises a proportion of the voucher scheme, and collects new taxes to fund it. In brief, some players in the economy pay more taxes, which are used as food subsidies. Households face lower food prices and receive higher wages, and buy more food and other commodities.

The main results of the simulations are provided in Table 1. The different columns depict different proportions of the food voucher scheme funded by the government, from no funding on the left, to full funding on the right. The first row contains the same values in every column, so I have kept the size of the programme constant, while changing the relative contributions by government and firms. The second row shows the change in nominal GDP, which only looks favourable when the government's contribution to the system is small. A few versions of multipliers are given in rows 9 to 11 in Table 1 to put the results into perspective. Row 9 shows the change in nominal GDP divided by the size of the government contribution to the scheme, and it is clear that the change in GDP per Rand contributed by the government becomes negative, as the government's contribution increases. This is not a very informative measure, however, since the size of the programme is not the net cost to society in terms of taxes collected. The implementation of the programme also influences all other taxes in the economy, and the net burden should be used as the cost of the programme to society. 


\section{Table 1}

Different taxing scenarios to fund the food voucher scheme

\begin{tabular}{|c|c|c|c|c|c|c|c|}
\hline & \multirow[t]{2}{*}{ Rm } & \multicolumn{6}{|c|}{ Government contribution to the food voucher scheme } \\
\hline & & $\mathbf{0} \%$ & $20 \%$ & $40 \%$ & $60 \%$ & $80 \%$ & $100 \%$ \\
\hline 1 & Size of programme & 154.31 & 154.31 & 154.31 & 154.31 & 154.31 & 154.31 \\
\hline 2 & Change in nominal GDP & 174.97 & 130.47 & 85.99 & 41.50 & -2.98 & -47.45 \\
\hline 3 & Nominal gov contribution & 0.00 & 30.86 & 61.73 & 92.59 & 123.45 & 154.31 \\
\hline 4 & Change in nominal tax revenue & 32.79 & 24.09 & 15.39 & 6.69 & -2.01 & -10.71 \\
\hline 5 & Change in capital related tax & 2.85 & 1.05 & -0.75 & -2.54 & -4.34 & -6.14 \\
\hline 6 & Change in real GDP & -88.85 & -73.89 & -58.95 & -44.01 & -29.08 & -14.16 \\
\hline 7 & Change in real tax revenue & -68.11 & -57.41 & -46.70 & -36.00 & -25.30 & -14.59 \\
\hline 8 & Change in indirect tax Rm & -0.27 & -0.68 & -1.10 & -1.52 & -1.94 & -2.36 \\
\hline 9 & $\triangle$ Nom GDP/ $\triangle$ Gov contr & $\infty$ & 4.23 & 1.39 & 0.45 & -0.02 & -0.31 \\
\hline 10 & $\Delta$ Nom GDP/ $\Delta$ Tax rev & 5.34 & 5.42 & 5.59 & 6.20 & 1.48 & 4.43 \\
\hline 11 & $\Delta$ Real GDP/ $\Delta$ Real Tax rev & 1.30 & 1.29 & 1.26 & 1.22 & 1.15 & 0.97 \\
\hline 12 & $\%$ Change in employment & -0.0239 & -0.0202 & -0.0164 & -0.0126 & -0.0089 & -0.0051 \\
\hline
\end{tabular}

Row 10 in Table 1 shows this measure better, namely the change in nominal GDP per net nominal tax Rand collected, results in quite positive multiplier effects. I could stop right here and argue that a food voucher scheme would be very beneficial to the economy; however this would belie the results obtained from a closer consideration of other factors and variables. In most columns, the nominal GDP increases by much more than the size of the net tax burden. Incidentally, the sizes of the multipliers in other studies resemble these orders of magnitude. I am convinced that most other studies in the food voucher literature ignored the general equilibrium price effects and the resulting values of real variables. However, prices and interest rates do change, and I should only be concerned with the effects on the real values of variables.

Row 11 in Table 1 shows the ratio between the changes in real GDP and the changes in net real tax revenue, as a result of the voucher scheme. The ratios look perfect, but the problem is that both real GDP and real tax revenue are always negative. No matter how large or small the government contribution to the voucher scheme is, the effects on both real GDP and real tax revenue would be negative.

\subsection{Industry results}

The only industries benefiting from a food voucher scheme would be the food industry and its direct suppliers, such as the agricultural industries, as well as hotels and restaurants. All other industries would be harmed by the implementation of the scheme. As the government's contribution increases, these industries benefit more and more. All other industries decrease production as a result of higher indirect taxes levied on their sales, to pay for the food voucher scheme.

The model results show that employment will always decrease, no matter what the size of government's contribution is. The higher its contribution the lower the impact on firms' hiring behaviour. With low government participation the impact on employment is severe, since firms' unit labour costs increase and they shed labour. 


\subsection{Explanation of results}

In brief, three forces are at play in the model when food vouchers are given to employees:

(i) The higher real cost of labour increases the total cost of production and therefore decreases the supply of most commodities.

(ii) The increases in take-home "wages" increase the demand for food and other commodities by households, which increases overall demand.

(iii) This is supplemented with subsidies on food products by the government, which further increase the demand for food.

With supply decreasing and demand increasing, there is an upward pressure on price levels, with the result that real values are smaller than nominal values, or even negative. Also, price increases of commodities reduce the competitiveness of South African commodities; resulting in decreasing exports, which has a further detrimental effect on GDP. I did not find a reference to foreign trade in other studies, but for South Africa, which is a small, open economy, this is a crucial aspect to the model. As expected, the food industry benefits greatly from the scheme.

The macroeconomic identity, $\mathrm{Y}=\mathrm{C}+\mathrm{I}+$ $\mathrm{G}+\mathrm{X}-\mathrm{Z}$ could be used to summarise the general equilibrium results. The left hand side depicts total income or production, and in the model, its sign is determined by capital and labour. Firms increase payments to employees - some of which are made in the form of food vouchers - and hence the cost of labour increases. Firms employ fewer labourers since the unit cost of labour increases. Capital and technology are fixed in the short-run, by assumption, so that total production decreases in the constant returns to scale economy. On the right hand side of the macroeconomic identity, I find that consumption expenditures (C) and imports ( $Z$ ) increase as a result of increased demand, while exports $(\mathrm{X})$ decrease, due to higher domestic prices. The net result on GDP is negative.

\subsection{Effects on poverty}

There are 12 household income groups in the model and the effects on the different groups' consumption are shown below. Even though average income statistics imply that South Africa is a middle-income country, most of the population experiences serious absolute poverty or is vulnerable to poverty (May, 2000)(Klasen, 2000). Poverty in South Africa is concentrated among the African and Coloured race groups. In 1995, the proportions of racial groups classified as poor included 61 per cent of Africans, 38 per cent of Coloureds, 5 per cent of Indians and 1 per cent of Whites (May, 2000). Aliber (2002) quoting Schlemmer's work based on the All Media and Products Surveys shows that overall poverty has increased since 1993 . A poverty line of R400 in 1989 Rand prices was used. Further, the data also shows that Africans and Coloureds remain the worst affected in terms of increasing poverty over the years, see Table 2 .

Table 2

Proportion of households below the poverty line

\begin{tabular}{|c|c|c|c|c|}
\hline & Africans & Coloureds & Indian & White \\
\hline 1989 & $51 \%$ & $24 \%$ & $6 \%$ & $3 \%$ \\
\hline 1993 & $50 \%$ & $26 \%$ & $8 \%$ & $3 \%$ \\
\hline 1996 & $57 \%$ & $22 \%$ & $9 \%$ & $3 \%$ \\
\hline 1997 & $55 \%$ & $21 \%$ & $6 \%$ & $4 \%$ \\
\hline 2001 & $62 \%$ & $29 \%$ & $11 \%$ & $4 \%$ \\
\hline
\end{tabular}

Source: Aliber (2002) 
Figure 1 shows a fascinating result of the modelling exercises, namely that the larger the government involvement in the food voucher scheme, the larger the benefits to the poorest household groups. On the horizontal axis the twelve household groups are depicted with the poorest group on the left, namely H01. If firms are funding the entire programme, richer households benefit proportionally more than poorer households and their total private consumption rises more. However, if government funds the programme, the poorest groups' consumption rises the most, while the richest group might even have a net decrease in consumption.

Figure 1

Per cent change in private consumption by household groups

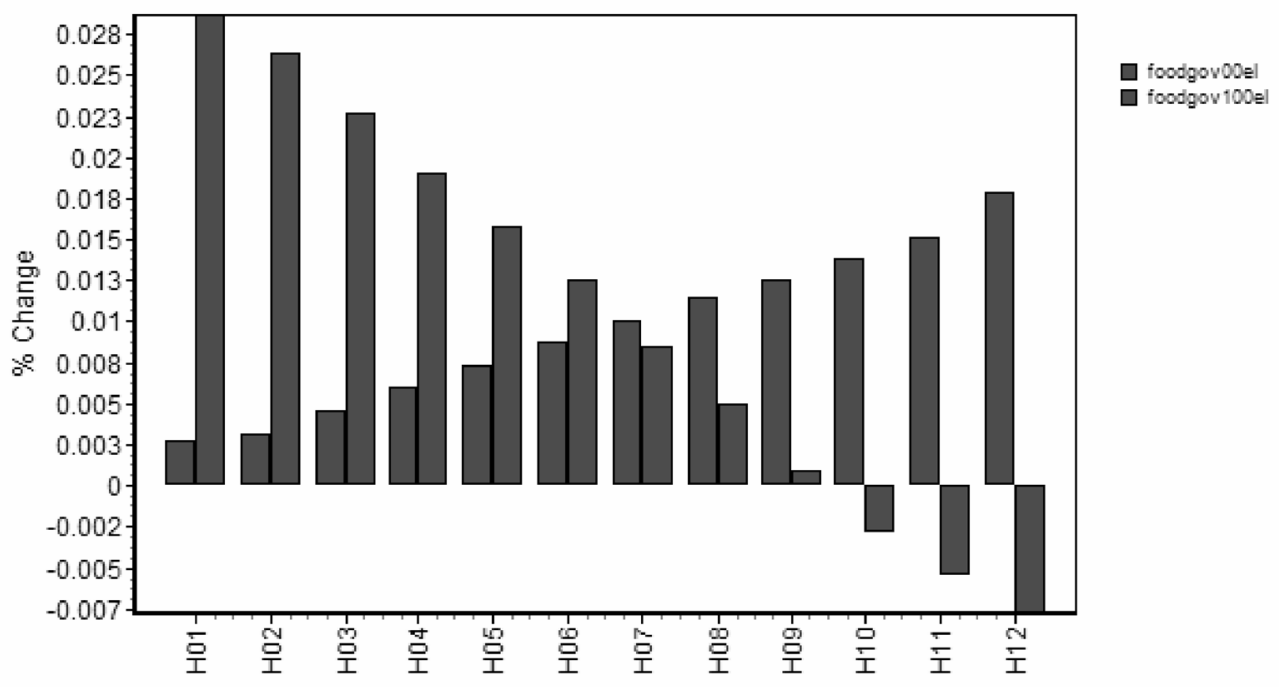

6

\section{Conclusion}

A food voucher scheme would mostly be a bad idea for South Africa. Whether the government partially or fully funds the food voucher scheme, it leads to negative effects on both real GDP and real tax revenue. The reason is simply that the scheme under review would distort prices in the economy, and make the country less competitive in world markets.

If firms are relied upon to co-fund such a scheme, their costs must increase, which would make production more expensive, and put upward pressure on prices, thereby exaggerating the harm done to the economy. Jobs would be lost, and South Africa can not afford that.

The only positive results that I found are that the poorest households would benefit more than the richest households, in an ideal modelling environment. In reality, they would probably sell their food vouchers for cash to buy other commodities, such as cigarettes and liquor. However, even though the poor may benefit more than the rich, there must be much better ways to relieve poverty, but that is a discussion for another time.

\section{7}

\section{Acknowledgement}

I would like thank Economic Research Southern Africa (ERSA) for generous financial support for this paper, which appeared as ERSA Working Paper nr 110 in an earlier format.

\section{References}

ALIBER, M.A. 2002. Overview of the incidence of poverty in South Africa for the 10-year review, Paper commissioned by the (South African) President's office. 
DE WET, T.J. 2003. The effect of a tax on coal in South Africa: A CGE analysis, Ph.D. Thesis, University of Pretoria, (http://upetd.up.ac.za/thesis/available/etd06302004-143319).

ERNST \& YOUNG. 2004. Assessing macroeconomic impact of food vouchers program in Lithuania $-a$ research report, Cape Town: Ernst \& Young. HARRISON, W.J. \& PEARSON, K.R. 1996. Computing solutions for large general equilibrium models using Gempack, Computational Economics, 9:83-127.

\section{INTERNATIONAL CENTRE FOR POLICY}

STUDIES. 2003. Assessing macroeconomic impact of food vouchers program in Ukraine. International Centre for Policy Studies. Kiev, Ukraine.

ICOSI, 2001. Meal vouchers - a tool serving the interests of the social pact in Europe. Place: ICOSI.
KLASEN, J. 2000. Measuring poverty and deprivation in South Africa. Review of Income and Wealth, 46(1):33-58.

MAY, J. (ed), 2000. Poverty and inequality in South Africa, meeting the challenge, Cape Town and London: David Phillip and Zeb Press.

SSA (Statistics South Africa). 2001. Social accounting matrix 1998, Pretoria: Statistics South Africa. VAN HEERDEN, J.H. et al., 2006. Fighting $\mathrm{CO}_{2}$ pollution and poverty while promoting growth: Searching for triple dividends in South Africa. The Energy Journal, 27(2): 113-142.

WANJEK, C. 2005. Food at work; workplace solutions for malnutrition, obesity and chronic diseases. 448p. International Labour Organisation. 


\section{Appendix \\ Modelling equations and their explanations}

Set FoodSet (Food,Hotels,Trade); ! to include restaurants, etc !

Subset Foodset is subset of COM;

Coefficient

FACEVALUE \# face value of food vouchers \#;

GOVCONT \# government contribution to firm cost of purchasing vouchers \#;

FIRMNETCOST \# net firm cost of purchasing vouchers \#;

MOREFOOD \# additional expenditure on food \#;

Formula $^{1}$

FACEVALUE $=0.001 *$ sum $\{$ f,FOODSET, V3PUR_S(f) $\} ;$ ! size of scheme !

The total value of the voucher scheme is a proportion of all spending on food by households

GOVCONT $=0.2 *$ FACEVALUE;

FIRMNETCOST $=$ FACEVALUE - GOVCONT;

MOREFOOD $=0.8 *$ FACEVALUE;

I assume that the government will contribute 20 per cent of the face value of the scheme, and that 80 per cent of the value of the vouchers will be spent on extra food. These assumptions can easily be changed without

changing the fundamental results.

Variable (change) delUnity; ! new exogenous...shock $=1$ !

Variable fFood_f; ! new exogenous !

Variable fgFood_f; ! new exogenous!

! increase in wage cost !

Variable (change) delWageBill;

Equation E_delWageBill \# definition \# delWageBill = 0.01*V1LAB_IOP*w1lab_iop;

Variable (change) delFW;

Equation E_delFW \# rule \# delWageBill = FIRMNETCOST*delUnity + delFW;

! to activate rule, swap delFW = f1lab_iop !

! increase in food spending !

Variable (change) delFoodSpend ;

Equation E_delFoodSpend \# definition \# delFoodSpend =

$0.01 * \operatorname{sum}\{\mathrm{f}$, FOODSET, V3PUR_S(f)*[x3_s(f) + p3_s(f)] $\}$;

! to enforce taste change toward food!

Variable (all,f,FOODSET) fFood(f);

Equation E_fFood \# rule \# (all,f,FOODSET) a3_s(f) = fFood(f) + fFood_f;

Variable (change) delF2;

Equation E_delF2 delFoodSpend $=$ MOREFOOD $*$ delUnity + delF2;

! to activate,

swap fFood $=$ A3_s(FOODSET);

swap delF2 = fFood_f; ! 
! gov contribution modelled as a food subsidy!

Variable (change) delGOVCONT;

Equation E_delGOVCONT \# definition \# delGOVCONT $=\operatorname{sum}\{f, F O O D S E T, \operatorname{sum}\{\mathrm{s}, \mathrm{SRC}, \operatorname{Delv} 3 \operatorname{tax}(\mathrm{f}, \mathrm{s})\}\}$;

Variable (all,f,FOODSET) fgFood(f);

Equation E_fgFood \# rule \# (all,f,FOODSET) f3tax_s(f) = fgFood(f) + fgFood_f;

Variable (change) delFG;

Equation E_delFG delGOVCONT = GOVCONT $*$ delUnity + delFG;

! to activate,

swap fgFood $=$ f3tax_s(FOODSET);

swap delFG = fgFood_f; ! 